\title{
A(S) FIGURA(S) DO(S) NARRADOR(ES) EM SUMMERTIME, DE J. M. COETZEE
}

\section{THE NARRATOR(S) IN J. M. COETZEE'S SUMMERTIME}

\author{
João Pedro Wizniewsky Amaral \\ Universidade Federal de Santa Maria, Santa Maria, Rio Grande do Sul, Brasil \\ Pedro Brum Santos \\ Universidade Federal de Santa Maria, Santa Maria, Rio Grande do Sul, Brasil
}

\begin{abstract}
Resumo: Summertime é o último volume da trilogia autoficcional Scenes from Provincial Life, de J. M. Coetzee. Esse romance apresenta uma narrativa híbrida: alguns capítulos são narrados em forma de diário e outros em forma de entrevista. A partir desses dois modos narrativos, nossa hipótese é que a figura do narrador nesse romance é mais que contar uma história: ele exerce os papéis (para)literários de autor, leitor e personagens. Neste artigo, discutiremos a problemática contemporânea da arte do narrar e analisaremos quais os efeitos desse(s) narrador(es) múltiplo(s) na narrativa. O narrador em Summertime não está morto, mas é versátil e volátil.
\end{abstract}

Palavras-chave: Narrador; narrativa híbrida; Summertime; J. M. Coetzee.

Abstract: Summertime is the latest Coetzee's novel from the auto-functional trilogy Scenes from Provincial Life. This novel presents a hybrid narrative: some chapters are narrated like a diary and others like interviews. From these two narrative modes, our hypothesis is that the narrator in this Coetzee's novel goes beyond narrating: he or she also plays the (para)literary roles of author, reader and characters. In this article, we intend to discuss the contemporary narrating problematic and to analyze the effects of the narrator(s) to this novel. The narrator at Summertime is not dead but is versatile and volatile.

Keywords: Narrator, hybrid narrative, Summertime, J. M. Coetzee.

\section{Introduçáo}

Summertime é o terceiro volume da trilogia autoficcional Scenes from Provincial Life, do escritor sul-africano J. M. Coetzee. Traduzido, aqui no Brasil, por Verão, o romance foi publicado em 2009 e tem Boyhood e Youth como os volumes anteriores. Ao estilo de um romance de formação, Boyhood e Youth narram, em terceira pessoa e no tempo presente, o crescimento do jovem John Coetzee em uma segregada África do Sul até 
sua viagem à Europa com intenção de se tornar um poeta. A narrativa desses dois romances é extremamente objetiva, e o narrador não é opinativo nem intrusivo. $\mathrm{O}$ foco narrativo, por sua vez, concentra-se exclusivamente no protagonista, e tanto a linguagem como a percepçáo dos eventos acompanham seu desenvolvimento.

Por outro lado, Summertime se distingue significativamente dos dois romances anteriores. A princípio, quando começamos a leitura de Summertime, podemos achar que a narrativa será semelhante aos outros tomos porque o primeiro capítulo é narrado em formato de um diário. $\mathrm{O}$ que, entretanto, chama a atenção são comentários escritos em itálico após os manuscritos que começam com expressóes como "a ser expandido" ou "continuação", seguidas de comentários acerca de determinada entrada do diário. Assim, o narrador póe em xeque a autoria desses trechos.

Apesar de o primeiro capítulo estar narrado em formato de um diário, todos os outros capítulos, com exceção do último, são narrados em forma de uma entrevista. O contexto da história é inusitado. John Coetzee, o personagem ficcional, agora está morto e um jovem biógrafo chamado Vincent se interessa por detalhes de sua vida privada, conduzindo entrevistas com pessoas próximas a Coetzee. Entâo, a narrativa de Summertime acontece em dois modos: um em formato de diário e outro em formato de uma entrevista.

A partir desses dois modos narrativos em Summertime, a hipótese deste artigo é que a figura do narrador nesse romance de Coetzee vai além da simples função de narrar, exercendo outros papéis (para)literários, como os de autor, leitor e personagens. Sendo assim, o narrador em Summertime é uma figura múltipla. Neste estudo, considerando essa hipótese, analisaremos quais os efeitos desse(s) narrador(es) na narrativa.

\section{Um romance, duas narrativas e um narrador plural}

Walter Benjamin, em um contexto pós-guerra, sentenciou que a "arte de narrar está em vias de extinção” (BENJAMIN, 1983, p. 197). Essa frase é impactante e há duas razôes para isso, segundo ele: as açôes da experiência estão em decadência, e a sabedoria está definhando. Se formos tomar essa hipótese por verdade, podemos considerar Summertime, por ser uma obra contemporânea, um romance cuja narrativa está mais perto da extinçáo do que aquelas da época em que Benjamin formulou sua crítica. 
Summertime funciona, como mencionado anteriormente, com dois tipos de narrativa: a de diário e a de entrevista, e em ambas podemos prontamente encontrar resquícios da tradição oral. Já na primeira, a narrativa de um diário, o narrador confronta a ideia de que as açôes de experiência estáo em baixa, posto que esse tipo de narrativa é elaborado basicamente a partir registro de experiência, o que o próprio Benjamin aponta como fonte das melhores narrativas: "a experiência que passa de pessoa a pessoa é a fonte a que recorreram todos os narradores. E, entre as narrativas escritas, as melhores são as que menos se distinguem das histórias orais contadas pelos inúmeros narradores anônimos" (BENJAMIN, 1983, p. 198).

Contudo, o que é inusitado nesse modo narrativo de diário são possíveis anotaçôes no fim de cada trecho de narrativas diárias. Expressóes em itálico como "a ser desenvolvido", "a ser expandido" ou "pergunta" são usadas para introduzir um comentário acerca do texto. Um exemplo disso está no trecho da introdução do dia 31 de Maio de 1975, relato de uma África do Sul prestes a decretar estado de guerra. $\mathrm{O}$ narrador desse fragmento alude à imagem de Jesus, afirmando que por causa de sua indiferença política, ele foi exterminado. Logo após esse trecho, lemos a seguinte expressão em itálico "Cuidado: evite ir longe demais no interesse dele por Jesus e transformar isso em uma narrativa de conversação a ser expandida" (COETZEE, 2009, p. 13, tradução nossa).

Aqui o narrador impóe uma quebra na narrativa: há um comentário que possivelmente seja narrado pelo biógrafo Vincent, visto que os trechos em itálicos se referem ao Coetzee, personagem, em terceira pessoa. Apesar disso, o biógrafo explica em uma das entrevistas que as anotaçóes são do próprio Coetzee: "Coetzee escreveu-se por si mesmo. Estas são memórias de si, escritas em 1999 ou 2000, quando ele estava pensando em adaptar essas postagens em um livro" (COETZEE, 2009, p. 20, tradução nossa). Se considerarmos a narrativa de Boyhood ou Youth como exemplos, podemos dizer que Coetzee escreve sobre si da mesma forma que nesses comentários: na terceira pessoa e no tempo presente. Portanto, nessa primeira parte de Summertime, temos um narrador que, embora se pareça muito com alguns da tradição realista, não podemos confirmar sua identidade.

O narrador dos diários, que provavelmente é o falecido Coetzee, registra suas experiências em seu caderno, e o biógrafo, por seu lado, está tentando transmitir a experiência de Coetzee através da confecção de sua biografia: um caso típico de troca de experiências que Benjamin cita. Temos, aqui, uma ironia sobre essa narrativa, pois o narrador brinca 
simultaneamente com a questáo de sua confiabilidade e da autoria do texto. Podemos nos perguntar se esse trecho é de fato de autoria de Coetzee, o personagem fictício, ou se ele já está manipulado por uma outra pessoa e se, de fato, as informaçóes do(s) narrador(es) podem ser tomadas como verdadeiras. Ademais, os comentários em itálico, após os comentários no diário, indicam uma possível releitura de suas anotaçóes, o que projeta ao narrador a figura de leitor.

Essa ironia é típica da literatura contemporânea, delegando ao leitor, entáo, a função de fazer as ligaçôes possíveis de uma história múltipla e fragmentada. Em romances realistas, por exemplo, o narrador geralmente é confiável porque a história já está aparentemente bem costurada: nessa tradição é raro encontrar lacunas no enredo, por exemplo. Fica a cargo do leitor, na tradição modernista, náo ligar os pontos desconexos da história, mas fazer outras aproximaçóes como figuras de linguagem. Já em Summertime, Coetzee alia formas narrativas tradicionais a narradores que podem vir a desmontar essa linearidade.

Uma possível implicação disso é que há uma possível transfiguração da figura do narrador na figura do leitor e do autor. Summertime extrapola qualquer tipo de pacto biográfico por abrir inúmeras possibilidades de identidade de narrador, personagens e de autoria fictícia. O narrador pode ser considerado o leitor, posto que ele mesmo modifica e indica possíveis explicaçóes para os trechos, além de ele comentar sobre passagens já escritas. E o narrador também pode ser o autor no sentido de o personagem ser um possível alter ego de Coetzee. Além do mais, Coetzee, o autor real, brinca com a possibilidade de múltiplos autores para o mesmo texto em outros romances, como nos dois volumes anteriores da trilogia, Slow Man (2006) e Elizabeth Costello (2003).

Podemos aproximar essa técnica narrativa ao romance Fogo Pálido, de Vladimir Nabokov, obra em que o narrador apresenta um poema que conseguiu de um poeta morto e divulga inúmeras notas explicativas sobre ele. Todavia, as notas explicativas não exercem de fato uma leitura guiada do poema, mas indicam leituras inesperadas, absurdas ou até mesmo de significaçóes opostas, em relação ao texto original. Tanto Nabokov quanto Coetzee problematizam nesses romances a questáo da confiabilidade do narrador e os problemas de autoria e de possíveis releituras do texto literário.

Summertime é um romance cuja figura do autor ultrapassa a barreira do real, e se torna todo um motivo narrativo e até um possível narrador. Qualquer ficção implica em uma autoria. Porém, de acordo com Hannah 
Arendt (2005), não podemos confundir a história da ficção com a história da autoria real:

A história de ficção revela um autor [...] e isso não se deve ao caráter da história em si, mas apenas do modo pelo qual ela veio a existir. A diferença entre a história real e a ficção é precisamente que esta última é feita enquanto a primeira náo o é. A história real, em que nos engajamos durante toda a vida, não tem criador visível nem invisível porque não é criada (ARENDT, 2005, p. 198).

Entretanto, o narrador de Summertime brinca com essa afirmação, revelando um caráter autoral e ficcional que ao mesmo tempo é e não é criado. Existe, sim, Coetzee autor, mas existe também o Coetzee personagem (e talvez até Coetzee narrador, na parte dos diários) que náo necessariamente são idênticos. Justamente os pontos que conectam autor e personagem seriam as memórias e as experiências relatadas, que ironicamente são descreditas pela figura do narrador ao apresentar indícios de contradição ou de diferentes autores. As experiências e memórias são instâncias que ligam todo o romance de Coetzee, cujos limites da representaçáo são testados a todo o tempo pelo narrador. Não sendo tão apocalíptico quanto Benjamin, seria melhor dizer, portanto, que a arte de narrar está perpetuamente experimentando, alterando-se e evoluindo. Ora, as memórias estão ali; elas só estão sendo contadas de modos diferentes.

Além da narrativa em forma de diário, Summertime apresenta majoritariamente uma narrativa em forma de entrevista, em que Vincent, o biógrafo de Coetzee, é o entrevistador e os entrevistados são pessoas que passaram pela vida de John Coetzee, o personagem - e por que não o autor? -. As entrevistas sempre aparecem através do discurso direto. Para exemplificar o modo narrativo peculiar desse último volume, eis um trecho da entrevista conduzida com Sophie, ex-colega de Coetzee na Universidade do Cabo:

Senhora Denöel, me conte como você conheceu John Coetzee

Ele e eu fomos por anos colegas na Universidade de Cabo. Ele era do Departamento de Inglês e eu do Departamento de Francês (COETZEE, 2009 , p. 221, tradução nossa).

Curiosamente, a entrevista é um método cuja validade Coetzee, ele próprio, questiona como meio de obter informaçôes, conforme registrado 
em sua conversa com David Atwell, no livro Doubling the Point (1992), mais de uma década antes de escrever Summertime.

\begin{abstract}
Uma entrevista nấo é apenas, como você chama, uma "troca": ela é, em nove a cada dez vezes (este é o décimo caso, graças a Deus!), uma troca com um completo estranho, mas um estranho permitido pelas convençốes do gênero para atravessar os limites do que é adequado nessa conversa entre estranhos. Eu não me considero uma figura pública, uma figura no domínio público. Eu não gosto de violação de propriedade, para não falar da violação do espaço privado, que geralmente ocorre na entrevista (ATWELL, 1992, p. 64-65, tradução nossa).
\end{abstract}

Para Coetzee, uma entrevista nunca é uma troca completa de informaçóes, mas uma espécie de invasão de privacidade por parte de um estranho a fim de descobrir alguma verdade. Coetzee defende também que sempre há um controle sobre a entrevista para captar uma verdade falada. $\mathrm{Na}$ opiniáo do autor, a verdade está relacionada ao silêncio, à reflexáo e à prática de escrever (ATWELL, 1992, p. 65-66).

A desconfiança de Coetzee em relação à entrevista, como método eficaz de buscar a verdade, parece dar-se por dois motivos. Primeiro, Coetzee enaltece a reflexão silenciosa, em que o sujeito se concentra sobre as contradiçôes que são os objetos de sua reflexão. Segundo, ele critica a violação do decoro que está implícita na entrevista. Nela, ocorre a transformação do sujeito entrevistado no objeto de observaçáo, em lugar de transformar o conteúdo do discurso do entrevistado no verdadeiro objeto de interesse.

Sobre o ímpeto do entrevistador em buscar a verdade através da entrevista, Coetzee pontua:

O ímpeto da surpresa exercido pelo magistrado ou pelo entrevistador não é um instrumento de verdade, mas, pelo contrário, uma arma, um sinal inerente da natureza de uma transação. O entrevistador se alinha com Robert Lovelace, personagem de Clarissa, de Samuel Richardson, o homem que acredita que a verdade está dentro do corpo do sujeito e que com sua armafalo pode procurá-la lá dentro (ATWELL, 1992, p. 66, tradução nossa).

A ideia do ato da troca (exchange), para Coetzee, parece mais complexa do que uma simples entrevista que tem caráter, muitas vezes, de improvisação, não permitindo uma consulta mais adequada do discurso dos envolvidos na discussão. $\mathrm{O}$ que vem à tona numa entrevista é a opinião e, ao que parece, Coetzee, ainda que aceitando as tensóes do ato de troca 
mútua (interchange), acredita que a verdade só pode ser aproximada através da investigação da consciência, que pode ser materializada com a prática da escrita, por exemplo. Conforme Coetzee, o discurso falado não é a fonte da verdade, mas uma versão pálida e provisória da versão escrita (ATWELL, 1992, p. 66).

Durante as entrevistas em Summertime obtemos certas dúvidas sobre a figura do narrador, do mesmo modo que problematizamos a narração em forma de diário. Quem é o narrador nessas entrevistas? Narratologicamente, as entrevistas estáo todas apresentadas por essas personagens apenas com o uso do discurso direto e em nenhum momento há uma intrusão de outra voz, senão as do entrevistador e do entrevistado. Logo, podemos considerar duas hipóteses: a) o narrador está ausente, pois somente as personagens falam; e b) tanto o biógrafo quanto os entrevistados são narradores em primeira pessoa. Mesmo que a narrativa seja apresentada no formato de entrevistas, há, de fato, açôes sendo narradas através do discurso, então não podemos dizer que o narrador não existe.

De qualquer modo, considerando o narrador de Summertime como opaco ou múltiplo, é interessante perceber os desdobramentos disso para o efeito da narrativa. Ao narrar somente as falas das personagens, tecnicamente teríamos um texto fundamentado e mais próximo de uma verdade, sem as informaçóes passarem pelo crivo de uma entidade como um narrador onisciente. Contudo, o(s) narrador(es) evidenciam que, mesmo assim, falhas e contradiçóes podem ocorrer em narrativas como essas.

No que tange ao conteúdo que Coetzee expóe em sua conversa teórica, notamos que as contradiçôes e as falhas de uma entrevista são materializadas pelo narrador de Summertime: em diversas vezes há divergências de dados ou fatos entre Vincent e o entrevistado. Podemos observar isso nesse trecho, em que a entrevistada Margot questiona se realmente contou tal história com tais palavras:

[Gemidos] Eu realmente disse isso tudo?

[Risos] Sim.

Quanta indiscrição de minha parte!

[Risos.] Não importa, continue (COETZEE, 2007, p. 98, tradução nossa)

Nessa entrevista com Margot, o narrador está realizando com ela uma segunda entrevista, para mostrar como ele condensou sua fala e como está será narrada na futura biografia de Coetzee. Vincent fala abertamente 
que ele pode ter modificado a própria história, dramatizando e deixando as pessoas falarem por si sós: "Só uma coisa. Já que a história que você contou era muito longa, entâo eu dramatizei aqui e ali, deixando as pessoas falarem por suas próprias vozes. Você verá o que eu quero dizer assim que começarmos" (COETZEE, 2009, p. 87, tradução nossa).

É importante ressaltar que, embora essa narrativa seja uma entrevista, o narrador não apresenta credibilidade ou confiabilidade para acreditarmos no que está sendo contado. Nessa mesma entrevista, mais adiante, Margot novamente pergunta: "Eu falei tudo isso? Eu não me lembro" (COETZEE, 2009, p. 105, tradução nossa); cuja resposta que recebe é que o Vincent adicionou um ou outro detalhe para dar vida à cena. Temos claramente aqui um artifício metanarrativo que questiona a confiabilidade do narrador simplesmente ao deixar as personagens falarem sem o intermédio de uma outra instância narrativa.

Outro aspecto que notamos nessa narrativa é que o narrador Vincent quer ditar seu próprio rumo da conversa. Sophie, uma professora universitária e ex-colega de Coetzee, indaga o entrevistador se ele tem autorização de expor o lado privado de sua vida e o biógrafo responde prontamente: "Ele [Coetzee] não pode me autorizar pela simples razão de que eu e ele nunca fizemos contato. Entáo vamos abandonar esse inquérito e retornar ao curso que você mencionou" (COETZEE, 2007, p. 227, tradução nossa). Vincent não está preocupado com as alegaçóes ou sugestóes da entrevistada, mas em falar sobre o tema que realmente lhe interessa (no caso um curso de literatura sul-africana). Isso corrobora a tese de Coetzee que a entrevista nunca é uma troca genuína de informaçóes ou experiências, pois, nesse caso, o biógrafo impóe o curso da entrevista.

A narrativa de Summertime talvez aponte que qualquer narrador, seja em primeira, segunda ou terceira pessoa, pode apresentar problemas de confiabilidade. Além do mais, a figura do narrador pode mesclar-se com outros elementos intra e extra-literários, como o autor, o leitor e as personagens. Ainda, da mesma forma, o narrador torna-se um paradoxo no ponto de vista de nós, leitores: necessitamos confiar nele, afinal, esse é um requisito básico para o leitor entrar no pacto literário (tomar consciência que determinada obra é uma ficçáo) e, ao mesmo tempo, nunca podemos confiar totalmente nele, independente da forma narrativa. Summertime é uma experimentação metaliterária, que junta diferentes narradores em diferentes modos narrativos, questionando a inflexibilidade de instâncias e escolhas literárias. 


\section{Consideraçóes finais}

Summertime possui dois tipos de narrativas: um em forma de diário com comentários e outro em forma de entrevista. Nesses dois modos, a figura do(s) narrador(es) aponta para duas questóes importantes: a confiabilidade do narrador e a possibilidade de o narrador migrar para outras instâncias da literatura.

As funçóes que o(s) narrador(es) de Summertime adquire(m) podem inclusive ser consideradas paraliterárias. Na narrativa em forma de diário, o narrador pode ser considerado ao mesmo tempo leitor e autor. Ele é leitor devido aos comentários após os registros e autor se considerarmos que esse é um diário real do próprio Coetzee. Já no que se refere à narrativa em forma de entrevista, o narrador, por apresentar somente falas através do uso do discurso direto, pode ser considerado múltiplo. O narrador é os próprios personagens. Em qualquer um desses casos, o narrador brinca com sua confiabilidade perante à história e ao leitor. Ao leitor é delegado o discernimento das contradiçôes da história, além da busca por brechas que o narrador proporciona.

A figura do narrador, embora possa parecer, não está morta. $\mathrm{Na}$ contemporaneidade ela é versátil e volátil. Summertime mostra-nos isso, enfatizando a ideia de Theodor Adorno (2003, p. 55), que considera que a posição do narrador "se caracteriza, hoje, por um paradoxo: não se pode mais narrar, embora a forma do romance exija a narraçáa”. Na atualidade, se é fato que não se tem a possibilidade/capacidade de narrar, o romance acha inúmeras formas e métodos narrativos que desconstroem ou dialogam com essa tradição.

Não obstante a estrutura de Summertime ser atípica para um romance, ele o é. Além do mais, a obra concilia dois conceitos que Benjamin diz serem duas coisas diferentes, a narrativa e o romance.

O que distingue o romance de todas as outras formas de prosas - contos de fada, lendas, e mesmo novelas - é que ele nem procede da tradiçáo oral nem o alimenta. Ele se distingue, especialmente, da narrativa. O narrador retira da experiência o que ele conta: sua própria experiência ou a relatada pelos outros. E incorpora as coisas narradas à experiência dos seus ouvintes. $\mathrm{O}$ romancista segrega-se. Escrever um romance significa, na descrição de uma vida humana, levar o incomensurável a seus últimos limites (BENJAMIN, 1983, p. 201). 
A principal característica Summertime que esse romance faz da linguagem é uma revolução, levando ao limite e até transfigurando instâncias literárias como o narrador. Ao mesmo tempo, podemos dizer que esse é um romance com um tom benjaminiano, porque o narrador está relacionado também às experiências pessoais (diários) - o camponês sedentário - e às relatadas pelos outros (entrevista) - o marinheiro mercante.

\section{Referências}

ADORNO, T. Notas de Literatura I. Sáo Paulo: Duas Cidades, 2003.

ARENDT, H. A condiçáo humana. Rio de Janeiro: Forense Universitária, 2005.

ATWELL, D. Doubling the point: Essays and Interviews by J. M. Coetzee. Cambridge: Harvard Press University, 1992.

BENJAMIN, W. O narrador: observações acerca da obra de Nicolai Leskov. In: BENJAMIN. W. et al. Os pensadores. São Paulo: Abril Cultural, 1983.

COETZEE, J. M. Boyhood: Scenes from Provincial Life. London: Penguin Group, 1997.

. Summertime: Scenes from Provincial Life. London: Harvill Secker, 2009.

2002.

Youth: Scenes from Provincial Life II. London: Penguin Group,

NABOKOV, V. Fogo Pálido. São Paulo: Círculo do Livro, 1989. 